\title{
Mechanical response of a fibre reinforced earthen material under static and impact loadings
}

\author{
Francesco Aymerich ${ }^{1}$, Luigi Fenu ${ }^{2}$, Luca Francesconi ${ }^{1, a}$, and Paola Meloni ${ }^{1}$ \\ ${ }^{1}$ Department of Mechanical, Chemical and Materials Engineering, University of Cagliari, Italy \\ ${ }^{2}$ Department of Civil and Environmental Engineering and Architecture, University of Cagliari, Italy
}

\begin{abstract}
This study examines the improvements provided by the insertion of hemp fibres with different weight fractions and lengths in an earthen material. The structural response of the materials was investigated by means of static and impact bending tests carried out on notched samples. The main focus of the analyses was in the characterization of the structural properties of the materials in terms of fracture resistance, post-cracking performance and energy absorption capability. The results of the study show that hemp fibres improve significantly the mechanical and fracture properties of the earthen material under both static and dynamic bending. It was also found that the structural properties of unreinforced and reinforced earthen materials are highly sensitive to the stress-rate, with higher strength and fracture resistance under impact loading than under static loading.
\end{abstract}

\section{Introduction}

In the last decades earthen materials have attracted considerable interest and regained importance in many fields of the construction sector, especially in developing countries and in rural, protected and architectural heritage areas [1-3]. Earth is widely used as building material in many hot or temperate regions and recent surveys estimate that more than one third of the world's population live in houses built of mud or unfired earth [4].

The reasons for the widespread adoption of unbaked earth-based construction materials are found in the abundance, low cost and recyclability of soil, and in the characteristics of the typical production processes, which are technologically simple and highly energy-efficient, besides having a very low carbon footprint, with little or no impact on the ecosystem and environment $[2,3]$. In addition, these materials provide excellent sound and thermal insulation [5,6], together with good fire resistance and humidity control properties.

Despite these advantages, the wider use of earth as primary building material has been hampered by some inherent limitations of the material, such as low tensile and flexural strength, poor fracture resistance and ductility, high propensity to drying shrinkage cracking, strong sensitivity to water erosion. These issues are especially critical in seismic areas or in the presence of critical climate conditions.

The low strength and the brittle behaviour are probably the major issues for structural use of earth-based materials, particularly for buildings and constructions likely to be subjected to seismic events [7,8]. For this reason, vegetal or animal fibres, including straw, flax, sisal, jute and wool [9-12], have been often used to improve the mechanical properties of the base material for specific

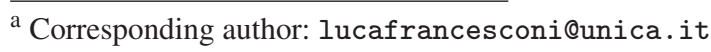

applications. However, only a very limited number of studies have been conducted to characterize the effect of fibrous reinforcement on fracture resistance, post-fracture performance and energy dissipation capacity of earthen materials [10-15]. As an example, Islam and Iwashita [13] showed that the insertion of straw or jute fibres effectively improved ductility and toughness of adobe materials, even if at the cost of a reduction in compressive strength. Increases in flexural strength and deformation capacity were also observed with the introduction of straw or wool fibres in plain [12] or notched earth-based samples [10,14].

On the other hand, to the authors' knowledge, no study has been yet reported on the influence of fibrous reinforcement on the fracture resistance and energy absorption properties of earth-based materials under dynamic loading conditions.

This study examines the improvements in strength, crack resistance and post-cracking performance achievable under static and dynamic (impact) loading conditions through the introduction of hemp fibres in an earthen building material. Notched samples made with soil material and reinforced with different fibre percentages and fibre lengths were manufactured and tested in a three point bending configuration. The results obtained under quasi-static and low-velocity impact loading are illustrated and discussed in the paper.

\section{Materials and method}

\subsection{Materials used}

A soil from quaternary sediments alongside the Tirso River near Oristano (Sardinia, Italy), traditionally used in the past to manufacture earth bricks, was used in this study. The granulometric curve of the soil, which was obtained by sieving and hydrometer analyses and carried out in accordance with ASTM standard D422 [16] shows

This is an Open Access article distributed under the terms of the Creative Commons Attribution License 4.0, which permits unrestricted use, distribution, and reproduction in any medium, provided the original work is properly cited. 
Table 1. Mixture proportions.

\begin{tabular}{cccc}
\hline $\begin{array}{c}\text { Mixture } \\
\text { designation }\end{array}$ & $\begin{array}{c}\text { Water/Soil } \\
\text { weight ratio }\end{array}$ & $\begin{array}{c}\text { Fibre } \\
\text { weight } \\
\text { fraction }\end{array}$ & $\begin{array}{c}\text { Fibre } \\
\text { length } \\
\text { (mm) }\end{array}$ \\
\hline $\begin{array}{c}\text { NFR } \\
\text { (Unreinforced) }\end{array}$ & 0.2 & $0 \%$ & N/A \\
\hline FRC-21 & 0.3 & $2 \%$ & 10 \\
FRC-22 & 0.3 & $2 \%$ & 20 \\
FRC-23 & 0.3 & $2 \%$ & 30 \\
\hline FRC-31 & 0.3 & $3 \%$ & 10 \\
FRC-32 & 0.3 & $3 \%$ & 20 \\
FRC-33 & 0.3 & $3 \%$ & 30 \\
\hline
\end{tabular}

that the soil may be classified as CL, i.e. inorganic clay with low plasticity and low liquid limit, in the Unified Soil Classification System (USCS) [17]. X-ray diffraction revealed the presence of dominant quartz, together with other constituents including illite and plagioclase. Grain size and values of Atterberg limits indicate that the soil is suitable for earth construction.

Hemp fibres with an average diameter of $0.2 \mathrm{~mm}$ were used to reinforce the earthen samples. Soil mixtures characterized by two fibre weight fractions ( $2 \%$ and $3 \%$ ) and three different fibre lengths $(10 \mathrm{~mm}, 20 \mathrm{~mm}$ and $30 \mathrm{~mm}$ ) were produced to examine the effect of fibre length and weight ratio on the structural properties of the reinforced material.

\subsection{Sample preparation}

Soil, hemp fibres and demineralized water were used to manufacture the samples. The soil collected from the cave was first manually treated to remove inclusions such as roots, rocks and other unwanted organic materials. The resultant material was then crushed using a mortar and a pestle, sieved using a $4 \mathrm{~mm}$ mesh, and finally desiccated using a drying oven (40 Celsius degree for 2 hours) to eliminate the residual humidity. The hemp fibres were manually combed and cut in 3 different lengths $(10 \mathrm{~mm}, 20 \mathrm{~mm}$ and $30 \mathrm{~mm})$, and used to prepare six mixture compositions characterized by different weight percentages and fibre lengths. Table 1 shows the mixtures used for manufacturing of samples.

Previous experiences and analyses were considered to determine the water content of the various mixtures so as to obtain similar levels of workability for the different mixture compositions [14]. The manufacturing of the specimens consisted in two steps: the soil and the fibres were dry mixed and the water was gradually added, while continuously mixing, up to the desired water/soil weight ratio. The mixture was then casted into perspex molds and manually compacted to form blocks $70 \times 70 \times 160 \mathrm{~mm}^{3}$ in size. All specimens were cured at room temperature for 30 days (for $48 \mathrm{~h}$ inside the moulds and for 28 days after demoulding) and at $40^{\circ} \mathrm{C}$ in an oven for 15 days. A central notch $35 \mathrm{~mm}$ in depth, as visible in Fig. 1, was finally cut in the mid section of the samples by a diamond coated circular saw blade.

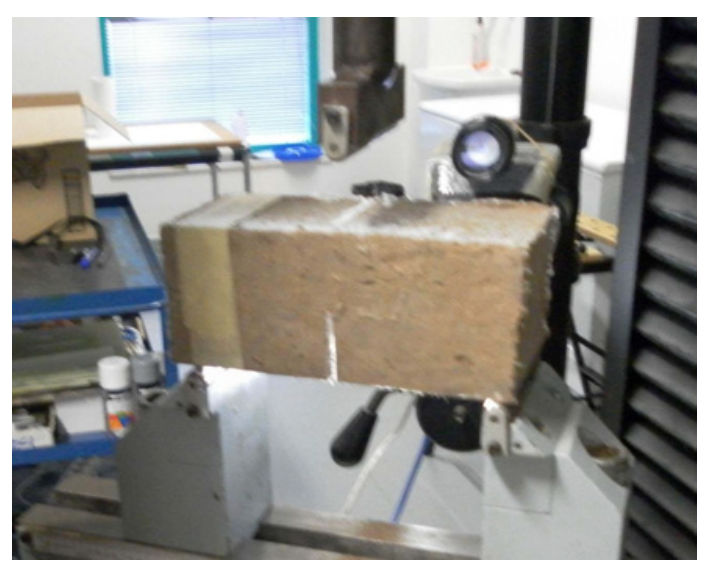

Figure 1. Fibre reinforced sample tested in the study.

\subsection{Experimental testing}

The notched specimens were tested to investigate the fracture performance of the unreinforced and reinforced materials under static and dynamic (impact) flexural loading. In particular, the experiments were focused on the analysis of the influence of different fibre contents and fibre lengths on the fracture resistance of the reinforced soil, and on the comparison of the energy absorption properties exhibited by the materials under different loading rates

During both static and impact testing, the bricks were loaded in a three-point bending configuration, using a distance between the supports (span length) of $140 \mathrm{~mm}$. The centre load was imposed through a steel solid cylinder with a diameter of $10 \mathrm{~mm}$.

Static tests were carried out using a closed-loop servoelectric $5 \mathrm{kN}$ tension/compression testing machine. Tests were conducted under displacement control at a rate of $1 \mathrm{~mm} / \mathrm{min}$. The mid-span deflection values were recorded using both the built-in displacement transducer of the testing machine (which measures the deflection at the loaded side of the beam) and a linear variable differential transducer (LVDT) positioned at the bottom side of the beam in the vicinity of the notch [14]. Since no significant differences were observed between the two measurements, only the deflection data acquired on the loaded side of the samples were considered in the analyses.

Impact tests were carried out using an instrumented drop-weight impact testing machine, provided with a $4.83 \mathrm{~kg}$ falling mass (Fig. 2). A pneumatic braking system capable of capturing the falling mass after the first rebound was used in order to prevent multiple impacts on the samples. All samples were impacted with an energy of about $50 \mathrm{~J}$, which corresponds to a drop height of approximately $1.05 \mathrm{~m}$ and to an impact velocity slightly higher than $4.5 \mathrm{~m} / \mathrm{s}$. The contact force between the impactor and the sample was measured by a piezoelectric force transducer mounted between the impactor tup and the drop weight. An infra-red sensor was used to measure the velocity of the impactor immediately before contact with the sample. The displacement and the kinetic energy of the impactor were calculated as a function of time by integration of the contact force signal. 


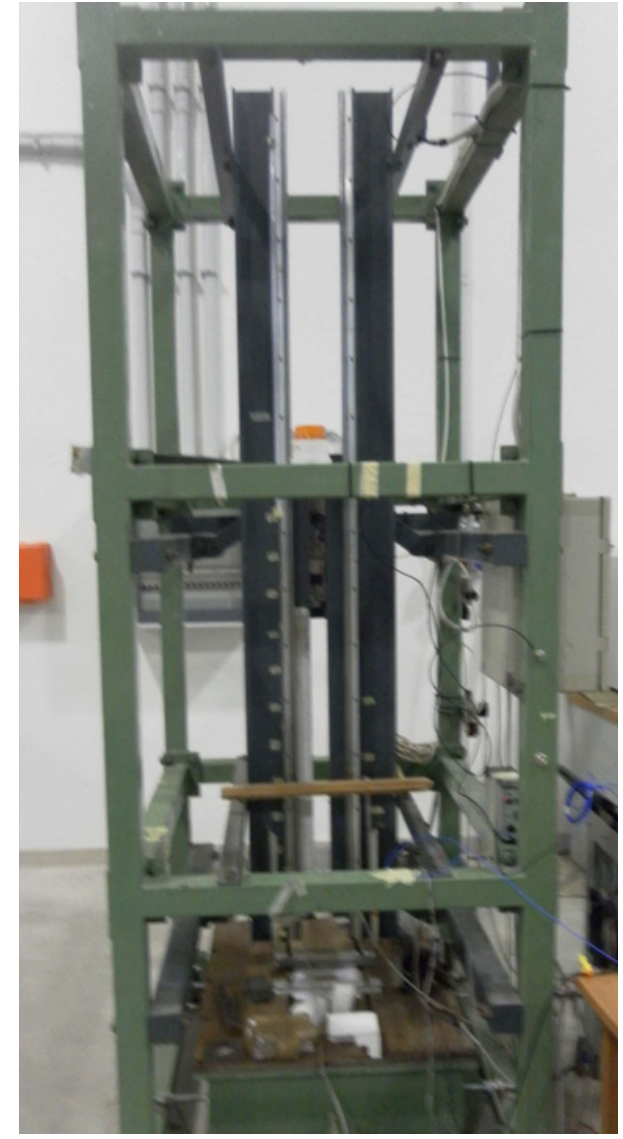

Figure 2. Impact testing fixture.

A minimum number of three samples were tested for any loading condition (static or dynamic) and for any of the mixtures investigated in the study.

\section{Results and discussion}

Typical force-deflection curves of unreinforced and reinforced samples subjected to quasi-static bending are presented in Fig. 3.

The plots of Fig. 3 clearly show that the introduction of hemp fibres greatly improves the mechanical properties of the soil material with regard to the residual strength and the energy absorption at large deflections.

As visible in the graphs, after an initial linear response, the force-deflection plot of the unreinforced material exhibits a sudden load drop, which corresponds to the fast propagation of a crack from the tip of the notch to the loaded side of the sample. Total loss of the flexural strength, with complete failure of the beam into two halves, was typically observed for maximum deflections of less than $1.5 \mathrm{~mm}$. In reinforced samples, in contrast, after the onset of first cracking phenomena at the notch (which are signalled by the slight slope reduction visible in the force-deflection curves after the initial linear stage) the force keeps increasing under increasing deflection until it reaches a peak load; beyond this point the force starts to slowly decrease, even if samples are seen to retain some residual strength up to bending deflections of $15 \mathrm{~mm}$ and
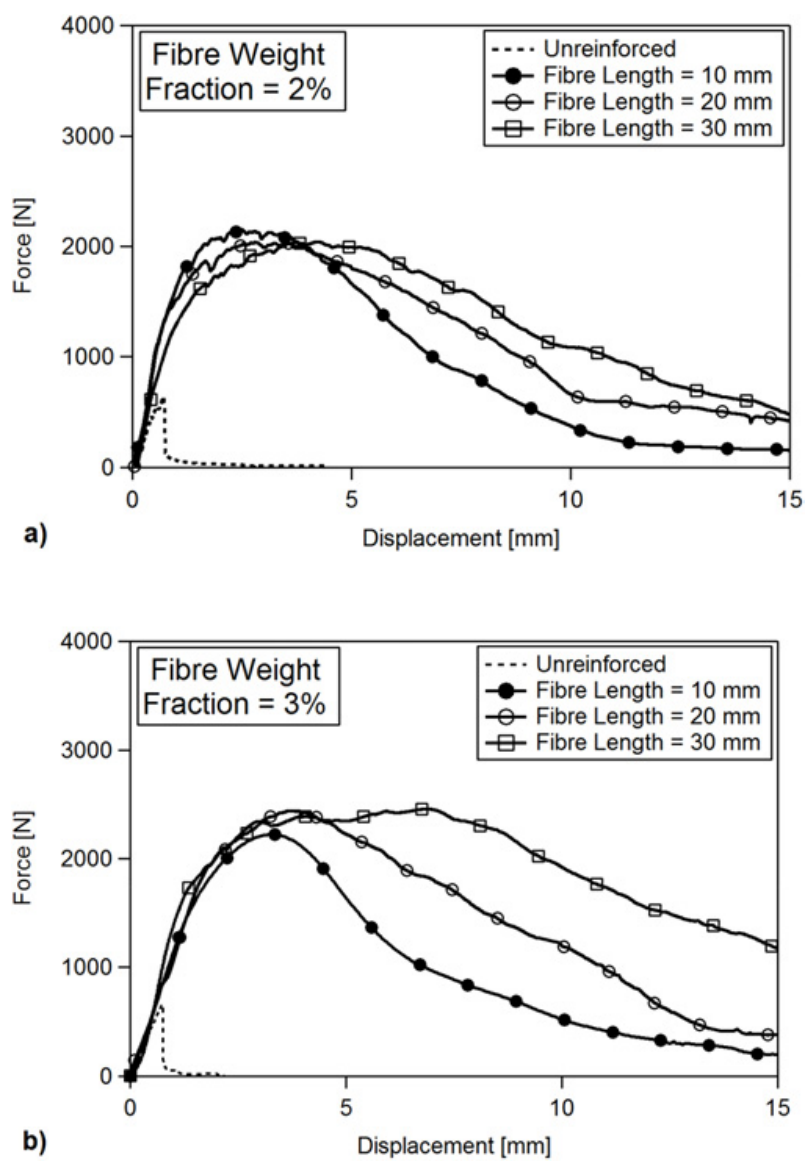

Figure 3. Force-displacement curves of unreinforced and reinforced samples subjected to quasi-static bending.

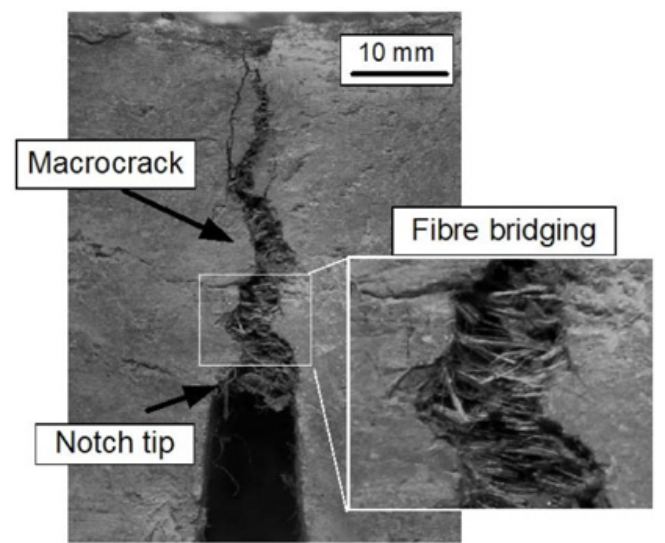

Figure 4. Fibre bridging across cracked surfaces in a sample reinforced with $2 \%$ of $10 \mathrm{~mm}$ fibres.

larger. The improvements in the load bearing capacity and in the fracture resistance produced by the fibrous reinforcement may be attributed to the bridging restraint provided by fibres across cracked surfaces (see Fig. 4), and to the energy dissipation associated to frictional sliding during pullout of debonded fibres at increasing deflections

The experimental results summarized in the plots of Fig. 3 indicate that the post-cracking properties of the reinforced materials are controlled by the fibre weight ratio 

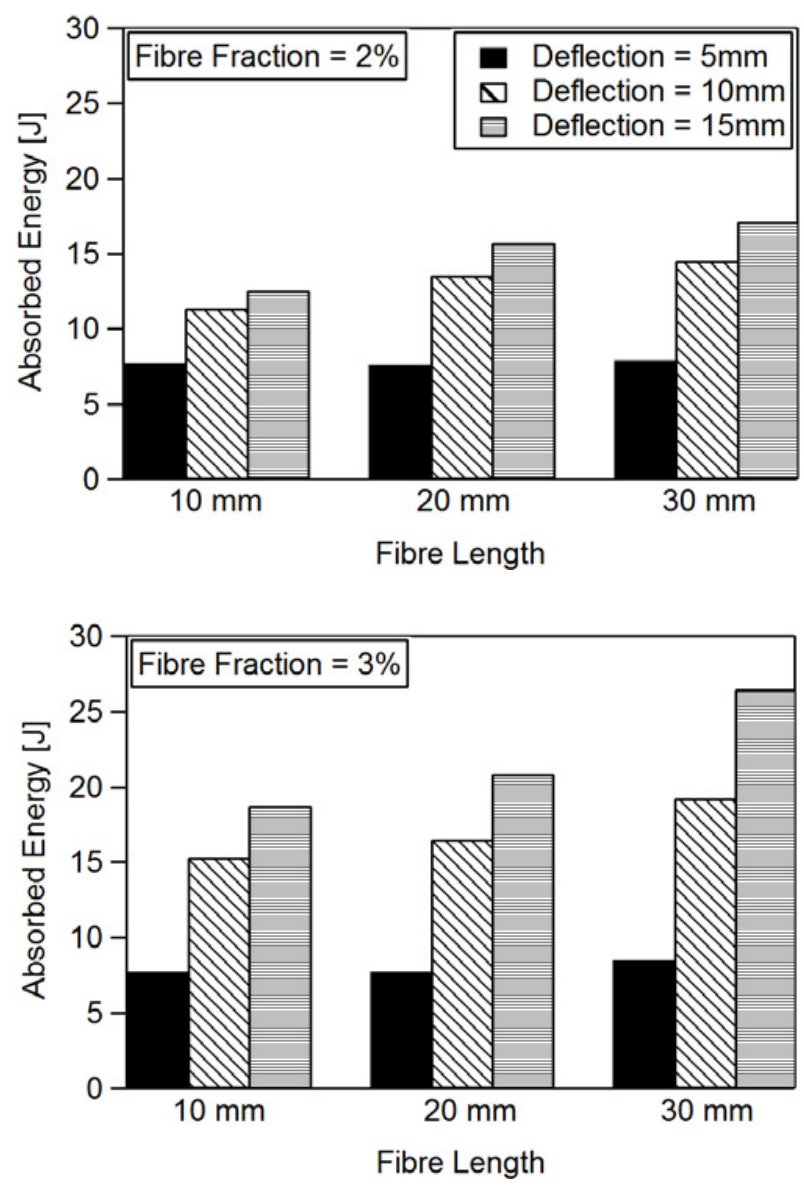

Figure 5. Average values of energy absorbed at different deflections by reinforced samples subjected to static bending.

and by the fibre length. It is clearly seen, in particular, that both the residual strength and the energy absorbed by the material at specific deflection levels increase with increasing fibre weight fraction and, for a constant fibre weight fraction, with increasing fibre length. As an example, the effect of fibre percentage and fibre length on the energy absorbed by the samples at different deflection levels is illustrated in the diagrams of Fig. 5. The energy absorbed by the samples was calculated as the area under the force-displacement curve up to the chosen deflection. We may observe that the energies absorbed at $10 \mathrm{~mm}$ and $15 \mathrm{~mm}$ deflections increase with increasing fibre content and fibre length. In contrast, the energy absorbed at $5 \mathrm{~mm}$ deflection does not appear to be significantly influenced by these parameters. These results indicate that large deflections (i.e. large crack openings) are required to fully activate the major mechanisms responsible for energy dissipation under bending loads, such as crack bridging and fibre debonding and pullout.

To examine the effect of the fibrous reinforcement on the fracture resistance of the materials under dynamic loading, three point bending tests were also carried out on the notched samples by an instrumented drop weight machine. The samples were simply supported on a support anvil using the same span length $(140 \mathrm{~mm})$ used during static tests and impacted with an energy of $50 \mathrm{~J}$. Because of the sample inertial effect, the load measured by the force transducer mounted on the impactor does not represent the actual bending load acting on the sample [18].

Following [18], the true impact force for bending was obtained by subtracting the generalized inertial force from the force measured at the impactor. The generalized inertial force was calculated as a function of the acceleration at the mid-span, assuming a linear distribution of the acceleration along the sample. The history of the acceleration of the sample at mid-span during the impact event was measured by an accelerometer placed on the lower side of the sample in the vicinity of the notch.

Typical force-deflection curves obtained during impact tests for the different material configurations are reported in Fig. 6.

The plots of Fig. 6 show that the impact response of the unreinforced material exhibits an abrupt load drop at a deflection of about $4 \mathrm{~mm}$, after which the load sustained by the sample quickly decreases to zero, as a result of the brittle collapse of the sample following the unstable propagation of a macrocrack from the notch tip. It should be observed however that the peak load measured during the impact is much larger than that recorded during quasistatic loading, thus indicating a strong sensitivity of the unreinforced material to the load rate.

A significant stress-rate sensitivity may also be observed in the structural response of the reinforced materials, as evident by comparison of the plots of Fig. 3 and Fig. 6. The analysis of static and dynamic force-deflections curves shows that all reinforced samples, irrespectively of fibre content and fibre length, exhibit higher peak loads, better residual strengths at large deflections, and larger energy dissipations under impact loading than under static conditions. As an example, a comparison of the static and impact responses of FRC-33 samples (fibre weight fraction $=3 \%$; fibre length $=30 \mathrm{~mm}$ ) reported in Figs. 3 and 6 indicate that the values of the peak load and of the residual strength at $15 \mathrm{~mm}$ deflection recorded during impact bending are, respectively, about $80 \%$ and $100 \%$ higher than those attained during static bending.

Average values of the energy absorbed by the samples at different deflection levels are shown in the diagrams of Fig. 7 as a function of fibre length.

The data reported in Figs. 5 and 7 confirm that the fracture resistance under high loading rates of this class of materials is significantly higher than that provided under static loading.

We may also notice that while fibre percentage and fibre length do not greatly affect the energy absorbed during impact for small deflections (see Fig. 7; $5 \mathrm{~mm}$ deflection), for larger deflections the energy absorbed during impact increases with increasing fibre weight fraction and, at a constant fibre weight fraction, with increasing fibre length (Fig. 7; $10 \mathrm{~mm}$ and $15 \mathrm{~mm}$ deflections).

The trends of these data are in accordance with those observed under static bending (Fig. 5), and this again indicates that the fracture response of the fibre-reinforced materials is governed by toughening mechanisms such as fibre bridging and fibre pullout only for sufficiently large crack opening displacements. 

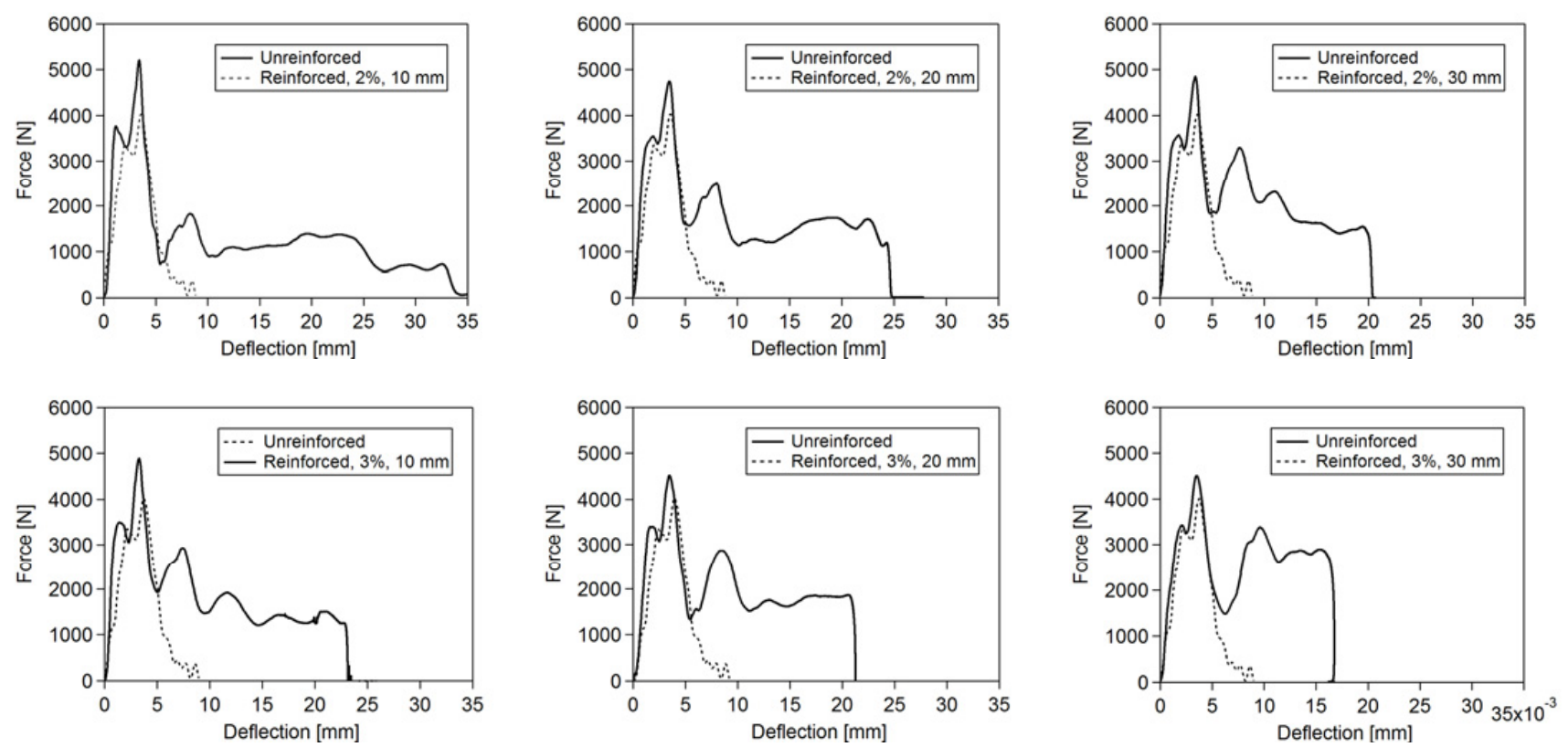

Figure 6. Force-displacement curves of reinforced and unreinforced samples subjected to impact bending.
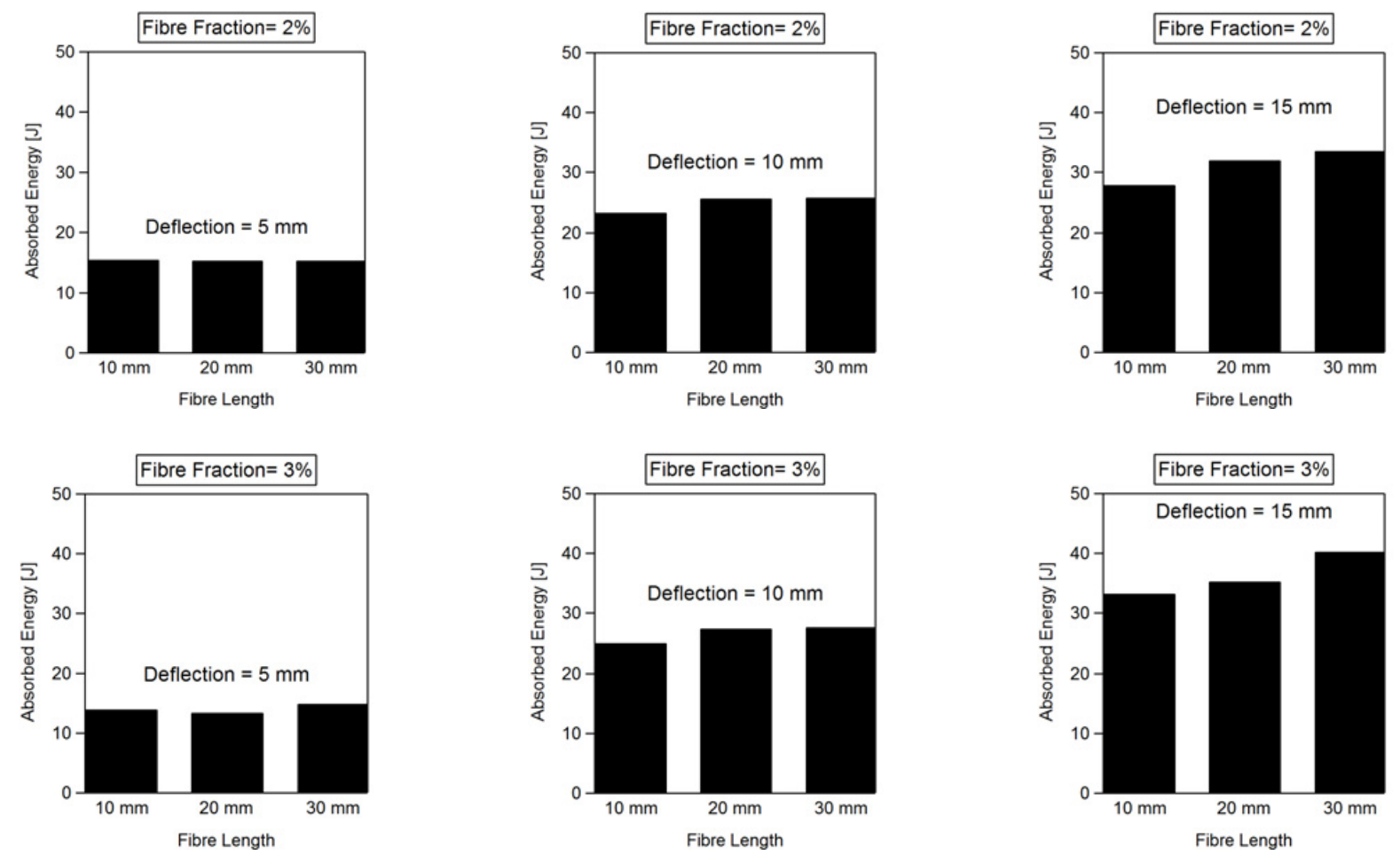

Figure 7. Average values of energy absorbed at different deflections by reinforced samples subjected to impact bending.

\section{Conclusions}

Notched earthen samples reinforced with hemp fibres were fabricated and tested under both static and dynamic bending. The main results of the analyses may be summarized as follows:

- The insertion of hemp fibres improves substantially the static and the dynamic mechanical properties of the earthen material.

- The strength and the fracture resistance of the earthen material increase with increasing fibre weight fraction and, for a constant fibre weight fraction, with increasing fibre length.

- Both unreinforced and reinforced earthen materials show a strong sensitivity to the loading rate, with significantly higher peak loads and energy absorptions under dynamic bending as compared to static bending.

- Bridging action, fibre debonding and fibre pullout are the key mechanisms responsible for the enhancement of strength and toughness of the base material.

The results indicate that reinforcement of earthen materials by hemp fibres represents an efficient way to enhance the 
structural performances of earth-based building materials under both static and dynamic loading conditions. Further investigations and more detailed analyses are however required to fully characterise the influence and relative importance of the different physical mechanisms by which fibres control strength and crack resistance properties of the material.

\section{References}

[1] H. Houben, H. Guillaud, Traité de construction en terre (Parenthèses, Marseille, 1989)

[2] G. Minke, Earth construction handbook: the building material earth in modern architecture (Wit Press, Southampton, 2000)

[3] G. Minke, Building with earth. Design and technology of a sustainable architecture (Birkhäuser, Basel, 2006)

[4] Avrami E., Guillaud H., Hardy M., Terra literature review: an overview of research in earthen architecture conservation. (The Getty Conservation Institute, Los Angeles, 2008)

[5] H. Binici,O. Aksogan, M. Nuri Bodur, E. Akca, S. Kapur, S. Thermal isolation and mechanical properties of fibre reinforced mud bricks as wall materials, Constr. Build. Mater. 21, 5 (2007)

[6] M. Bouhicha, F. Aouissi, S. Kenai, Performance of composite soil reinforced with barley straw, Cem. Concr. Compos. 27, 5 (2005)

[7] Q. Piattoni, E. Quagliarini, S. Lenci, Experimental analysis and modelling of the mechanical behaviour of earthen bricks, Constr. Build. Mater. 25(4), 9 (2011)

[8] H. Binici, O. Aksogan, T. Shah, Investigation of fibre reinforced mud brick as a building material, Constr. Build. Mater. 19, 8 (2005)
[9] K. Ghavami, R.D. Toledo Filho, N.P. Barbosa, Behaviour of composite soil reinforced with natural fibres, Cem. Concr. Compos. 21, 10 (1999)

[10] F. Clementi, S. Lenci, T. Sadowski, Fracture characteristics of unfired earth, Int. J. Fract. 149, 8 (2008)

[11] C. Galán-Marín, C. Rivera-Gómez, J. Petric, Claybased composite stabilized with natural polymer and fibre, Constr. Build. Mater. 24, 6 (2010)

[12] C. Galán-Marín, C. Rivera-Gómez, J. Petric, Effect of animal fibres reinforcement on stabilized earth mechanical properties, J Biobased Mater. Bioenergy 4(2), 7 (2010)

[13] M.S. Islam, K. Iwashita, Seismic response of fiber-reinforced and stabilized adobe structures, Proceedings of the Getty Seismic Adobe Project 2006 Colloquium (2006)

[14] F. Aymerich, L. Fenu, P. Meloni, Effect of reinforcing wool fibres on fracture and energy absorption properties of an earthen material, Constr. Build. Mater. 27, 6 (2012)

[15] F. Parisi, D. Asprone, L. Fenu, A. Prota, Experimental characterization of Italian composite adobe bricks reinforced with straw fibers, Compos. Struct. 122, 300 (2015)

[16] ASTM Standard D422-63, Standard test method for particle-size analysis of soils (ASTM International, 2007)

[17] ASTM Standard D2487-11, Standard practice for classification of soils for engineering purposes (Unified Soil Classification System), (ASTM International, 2011)

[18] N. Banthia, S. Mindess, A. Bentur and M. Pigeon, M. (1989). Impact testing of concrete using a drop-weight impact machine, Exp. Mech. 29(1), 7 (2010) 